\title{
Prognosis of the very low birthweight baby in relation to gender
}

\author{
M BROTHWOOD, D WOLKE, H GAMSU, J BENSON, AND D COOPER \\ Department of Child Health and Computer Unit, King's College School of Medicine and Dentistry, London
}

SUMmARY The effects of gender on mortality and morbidity of all neonates weighing $<1500 \mathrm{~g}$ admitted to King's College Hospital Neonatal Intensive Care Unit during 1980-82 (n=271) were examined. Very low birthweight boys had a significantly higher mortality and more postnatal complications than girls. The higher incidence of respiratory distress syndrome and pulmonary interstitial emphysema in boys was associated with increased mortality in the first year. Surviving boys had significantly more problems, including lower Apgar scores at five minutes, more frequent apnoeic attacks and bradycardic episodes, transient tachypnoea, neonatal anaemia, and lower blood calcium and phosphate concentrations. Surviving children were followed up at 1 and 2 years of age. Development of boys at 1 year was significantly delayed compared with girls in all fields save locomotor. Although at 2 years some of the differences had diminished, those in language and personal social skills were more pronounced. More than twice as many boys as girls had major neurodevelopmental disorders.

The relative vulnerability of boys to perinatal mortality and morbidity has been documented in perinatal studies. ${ }^{12}$ In particular, a greater incidence of problems in pregnancy and complications of delivery, birth asphyxia and neurological signs in the neonatal period, ${ }^{34}$ a higher incidence of infections, including those occurring after prolonged rupture of membranes, ${ }^{5}$ and congenital malformations ${ }^{6}$ have been reported in boys. Hyaline membrane disease ${ }^{7}$ and transient symptomatic hypoglycaemia have been found more often in preterm boys. In general, prospective studies of socioemotional and intellectual development repeatedly found boys to have more aggressive and hyperactive behaviour than girls. ${ }^{8}$ It has been noted that girls begin to speak earlier than boys. ${ }^{9}$ There is also a tendency for boys to be among the low scorers in verbal tests while there is no sex difference in the group of high scorers. ${ }^{8}$ In one study very low birthweight boys had lower intelligence quotient (IQ) scores than girls at 3 years, ${ }^{10}$ but most reports on the effects of gender on behaviour have centred on older children and have reported little or no difference. Only a few studies have investigated differential development in boys and girls in infancy.

This study examines (a) whether gender differences reported for the general neonatal population in regard to mortality and morbidity are apparent in a high risk very low birthweight population, and (b) whether gender differences in early developmental progress can be partly explained by differences in perinatal and postnatal morbidity.

\section{Patients and methods}

The sample consisted of 271 neonates of birth weight $<1500 \mathrm{~g}$, cared for in the Neonatal Intensive Care Unit of King's College Hospital between January 1980 and December 1982 inclusive. The 141 boys and 130 girls were born to mothers in the hospital catchment area or were referred in utero before birth or shortly after birth for intensive care. The social class of the parents of study infants was predominantly social class IIIb (Registrar General Classification of Occupations, 1980).

All survivors were assessed in the first two years by one of us (MB). One infant was assessed at another London teaching hospital at the age of 1 and 2 years using different developmental tests. Six children were not available for assessment at 1 year at our hospital. Five had moved, information about their clinical and developmental state at 1 year being given to us by their health visitors or general practitioners. One infant was assessed at home but was too unwell with a respiratory tract infection to complete the developmental assessment, and the family then moved abroad. These six children were all assessed at 2 years. By this time a further child's 
family had moved abroad. He had been assessed as normal by us at 1 year and was reported to be normal at 2 .

A list of 74 variables, including demographic information and data on pregnancy, delivery, and neonatal course, were collected prospectively and recorded on standard forms.

Development was assessed at 1 year using Knobloch and Pasamanick's development screening test. ${ }^{11}$ This assessment, like the Griffiths' scales, is adapted from Gesell's developmental scales ${ }^{12}$ and is highly correlated with the Griffiths' test at one year (A. Stewart. Personal communication, 1985). It assesses the following areas: adaptive functioning, gross and fine motor abilities, verbal skills, and personal social skills.

At 2 years the Griffiths' scales were used, ${ }^{13}$ which assessed the locomotor, personal social, hearing and speech, eye and hand coordination, and performance skills. Both assessments allow for general developmental quotients and subquotients to be calculated. A full clinical and neurological examination was also carried out at 1 and 2 years.

\section{Results}

\section{Sex differences in mortality and morbidity.}

The total study sample $(n=271)$

The mean (SD) birth weight for boys was 1116.5 $(229 \cdot 7) \mathrm{g}$ and for girls was $1169 \cdot 2(223.4) \mathrm{g}$. These did not differ significantly. Altogether, 105 (74\%) boys and $92(71 \%)$ girls were white. A number of significant sex differences were found in the total population of newborns (survivors plus deaths). The mean age of the mothers of boys (25.5 (SD 5.4) years) was nearly two years younger than that of girls $(27.3(5.9)$ years $)(p=0.009)$, and more girls were born by caesarian section (Table 1 ).

The state of boys after delivery as judged by the mean Apgar score at one minute was poorer than that of girls, $(4.7(\mathrm{SD} 2.7) v 5.4(2.8) ; \mathrm{p}=0.05)$ and remained lower at five minutes $(7 \cdot 1(2 \cdot 3) v 7 \cdot 9(2 \cdot 1)$; $\mathrm{p}=0.001$ ), and they had a higher incidence of hypothermia (Table 1). Recurrent episodes of bradycardia occurred more often in boys, and more boys experienced respiratory distress syndrome, pulmonary interstitial emphysema, and pneumothorax. Pneumonia and intraventricular haemorrhage occurred more often in boys. The greater severity of respiratory disease in boys was additionally reflected in the increased need for ventilation and higher ventilating pressures.

Boys required blood transfusions for anaemia more often than girls and more of them had umbilical arterial catheters inserted. No significant differences in the other variables mentioned above were found.

Non-survivors $(n=83)$

The overall sample was split into survivors and those

Table 1 Percentage of boys and girls positive for neonatal variables and significant diffferences for boys $\mathrm{v}$ girls in these variables by $\chi^{2}$ test

\begin{tabular}{|c|c|c|c|c|c|c|c|c|c|c|c|c|}
\hline \multirow[t]{2}{*}{ Variable } & \multicolumn{4}{|c|}{ All infants } & \multicolumn{4}{|c|}{ Survivors } & \multicolumn{4}{|c|}{ Non-survivors } \\
\hline & $\begin{array}{l}\text { Boys } \\
(n=14 I)\end{array}$ & $\begin{array}{l}\text { Girls } \\
(n=130)\end{array}$ & $\chi^{2}$ & $\begin{array}{l}p \\
\text { Value }\end{array}$ & $\begin{array}{l}\text { Boys } \\
(n=83)\end{array}$ & $\begin{array}{l}\text { Girls } \\
(n=105)\end{array}$ & $x^{2}$ & $\begin{array}{l}p \\
\text { Value }\end{array}$ & $\begin{array}{l}\text { Boys } \\
(n=58)\end{array}$ & $\begin{array}{l}\text { Girls } \\
(n=25)\end{array}$ & $x^{2}$ & $\begin{array}{l}p \\
\text { Value }\end{array}$ \\
\hline Multiple births & $17 \cdot 7$ & $23 \cdot 1$ & $1 \cdot 20$ & NS & $12 \cdot 0$ & $25 \cdot 7$ & 5.47 & $<0 \cdot 05$ & $25 \cdot 9$ & $12 \cdot 0$ & 1.98 & NS \\
\hline Non-white race & $25 \cdot 5$ & $29 \cdot 2$ & 0.47 & NS & $25 \cdot 3$ & $22 \cdot 9$ & 0.15 & NS & $25 \cdot 9$ & $56 \cdot 1$ & 6.98 & $<0.01$ \\
\hline Previous miscarriage & $40 \cdot 4$ & $38 \cdot 5$ & 0.11 & NS & $48 \cdot 2$ & $35 \cdot 2$ & $3 \cdot 2$ & NS & $29 \cdot 3$ & $52 \cdot 0$ & 3.9 & $<0 \cdot 05$ \\
\hline Pre-eclampsia & $22 \cdot 0$ & $25 \cdot 4$ & 0.43 & NS & $18 \cdot 1$ & $30 \cdot 5$ & $3 \cdot 8$ & NS & $27 \cdot 6$ & $4 \cdot 0$ & 5.97 & $<0 \cdot 05$ \\
\hline Hypothermia & $56 \cdot 0$ & $34 \cdot 0$ & $12 \cdot 50$ & $<0 \cdot 001$ & $41 \cdot 0$ & $28 \cdot 6$ & $3 \cdot 17$ & NS & $77 \cdot 6$ & $60 \cdot 0$ & $2 \cdot 69$ & NS \\
\hline Apnoea & $47 \cdot 5$ & $37 \cdot 7$ & $2 \cdot 67$ & NS & 59.0 & $36 \cdot 2$ & 9.73 & $<0 \cdot 01$ & $31 \cdot 0$ & $44 \cdot()$ & 1.29 & NS \\
\hline Bradycardia & $52 \cdot 5$ & $36 \cdot 9$ & $6 \cdot 62$ & $<0 \cdot 05$ & 51.8 & $35 \cdot 2$ & $5 \cdot 21$ & $<0.05$ & $53 \cdot 4$ & $44 \cdot 0$ & 0.62 & NS \\
\hline Respiratory distress syndrome & $57 \cdot 4$ & $40 \cdot 8$ & $7 \cdot 53$ & $<0 \cdot 01$ & $45 \cdot 8$ & $40 \cdot 0$ & 0.63 & NS & $74 \cdot 1$ & $44 \cdot 0$ & 6.98 & $<0 \cdot 01$ \\
\hline Transient tachypnoea & $10 \cdot 6$ & $7 \cdot 7$ & 0.70 & NS & $16 \cdot 9$ & $7 \cdot 6$ & $3 \cdot 84$ & $<0.05$ & $1 \cdot 7$ & $8 \cdot 0$ & 1.98 & NS \\
\hline Pulmonary interstitial emphysema & $36 \cdot 9$ & $14 \cdot 6$ & $17 \cdot 30$ & $<0 \cdot 001$ & $24 \cdot 1$ & $13 \cdot 3$ & 3.63 & NS & $55 \cdot 2$ & $20 \cdot 0$ & 8.75 & $<0 \cdot 01$ \\
\hline Pneumothorax & $20 \cdot 6$ & $10 \cdot 8$ & $4 \cdot 86$ & $<0.05$ & $10 \cdot 8$ & $7 \cdot 6$ & 0.59 & NS & $34 \cdot 5$ & $24 \cdot 0$ & 0.89 & NS \\
\hline Pneumonia & $30 \cdot 5$ & $22 \cdot 3$ & $2 \cdot 33$ & NS & $31 \cdot 3$ & $18 \cdot 1$ & $4 \cdot 46$ & $<0 \cdot 05$ & $29 \cdot 3$ & $40 \cdot 0$ & 0.91 & NS \\
\hline Intraventricular haemorrhage & $34 \cdot 8$ & $23 \cdot 8$ & $3 \cdot 87$ & $<0 \cdot 05$ & $25 \cdot 3$ & $21 \cdot 9$ & $0 \cdot 30$ & NS & $48 \cdot 0$ & $32 \cdot 0$ & $1 \cdot 88$ & NS \\
\hline Ventilated & $70 \cdot 9$ & $48 \cdot 5$ & $14 \cdot 24$ & $<0 \cdot(001$ & $56 \cdot 6$ & $40 \cdot 0$ & $5 \cdot 14$ & $<0 \cdot 05$ & $91 \cdot 4$ & $84 \cdot 0$ & 0.98 & NS \\
\hline Ventilating pressure $>20 \mathrm{cmH}_{2} \mathrm{O}$ & $33 \cdot 3$ & $14 \cdot 6$ & $12 \cdot 86$ & $<0 \cdot 001$ & $18 \cdot 1$ & $7 \cdot 6$ & $4 \cdot 72$ & $<0.05$ & $55 \cdot 2$ & $44 \cdot 0$ & 0.87 & NS \\
\hline Unbilical arterial catheter & $54 \cdot 1$ & $34 \cdot 7$ & $9 \cdot 82$ & $<0 \cdot 01$ & $41 \cdot 0$ & $31 \cdot 4$ & $1 \cdot 84$ & NS & $76 \cdot 0$ & $20 \cdot 8$ & $3 \cdot 55$ & NS \\
\hline Blood transfusion & $70 \cdot 4$ & $43 \cdot 4$ & $20 \cdot 30$ & $<0 \cdot(001$ & $65 \cdot 1$ & $41 \cdot 0$ & $10 \cdot 79$ & $<0 \cdot 001$ & $77 \cdot 6$ & $52 \cdot 0$ & $5 \cdot 43$ & $<0 \cdot 05$ \\
\hline Intralipid infusion & & $\star$ & & & $34 \cdot 9$ & $21 \cdot 9$ & 3.94 & $<0 \cdot 05$ & & $\star$ & & \\
\hline Serum calcium $(<1.75 \mathrm{mmol} / \mathrm{l})$ & & $\star$ & & & $49 \cdot 4$ & $33 \cdot 3$ & 4.97 & $<0 \cdot 05$ & & $\star$ & & \\
\hline Serum phosphate $(<1.3 \mathrm{mmol} / \mathrm{l})$ & & $\star$ & & & $31 \cdot 3$ & $13 \cdot 3$ & 9.0 & $<0.01$ & & $\star$ & & \\
\hline
\end{tabular}

$\star$ Excluded because of missing values for babies that died. 
who died within the first year (one boy died of sudden infant death syndrome at 16 weeks; the remainder died before leaving hospital). Perinatal and postnatal factors in surviving and non-surviving babies were analysed to examine sex differences in morbidity and mortality. The overall survival rate in $1980-82$ was $69 \%$. Boys accounted for the majority of infant deaths. While 58 out of $141(41 \%)$ of boys died during the first year of life, the mortality of 25 out of $130(19 \%)$ for girls was significantly lower $\left(\chi^{2}=15 \cdot 3, p<0 \cdot 001\right)$.

In those who died there were no significant differences in mean gestation, maternal age, and Apgar scores. More girls were of non-white origin, however, and a history of previous miscarriage was more common in the mothers of girls (Table 1 column 3). Pre-eclampsia occurred more often in the mothers of boys.

More boys than girls who died had respiratory distress syndrome or pulmonary interstitial emphysema. More girls died of necrotising enterocolitisthe only neonatal variable that showed girls at a disadvantage relative to boys. Boys had blood transfusions for anaemia more often than girls.

The early neonatal morbidity of boys was increased relative to girls. They had lower mean Apgar scores at five minutes $(7 \cdot 6$ (SD 2.1) $v 8.2$ $(1.8) ; p<0.05)$ and more episodes of apnoea and bradycardia. They also experienced transient tachypnoea and pneumonia more often than girls. They were ventilated more often, required higher ventilating pressures, and were more likely to be given oxygen. Anaemia (lowest haemoglobin 10.2 (SD 2.1) g v 11.6 (3.7) g) and the need for blood transfusion occurred more often in surviving boys, and they were given Intralipid infusion more often than were the girls.

Sex differences in early development. The general development quotients at 1 and 2 years and the subtests were compared for sex differences. The mean development quotients at 1 and 2 years for chronological and corrected ages are presented in Table 2. The significant differences are the same whether the development quotient is corrected for prematurity or not. The general development quotient of boys is significantly lower than that of girls at 1 and 2 years. Boys scored lower than girls at 1 year in nearly all areas of development. In particular, boys scored less in the adaptive subtests, had poorer fine motor control, and had less pre-verbal ability and their personal social skills were less well developed than those of girls. There was no significant difference between the sexes in gross motor behaviour. At 2 years the differences in verbal and personal social skills were found to have increased.
No significant differences were detected in their fine motor or locomotor skills nor in the cognitive performance field.

Major neurodevelopmental sequelae. Neurodevelopmental abnormalities identified by 2 years included cerebral palsy, sensorineural hearing loss, visual disorders such as delayed visual maturation, retinopathy of prematurity, and an overall developmental delay of sufficient severity to predict mental retardation (general development quotient $<70$ ). ${ }^{14}$ Over $11 \%$ (21 out of 188 ) of all infants had major neurodevelopmental disorders. Out of these 21 infants, 14 were boys $\left(\chi^{2}=4 \cdot 86 ; p=0 \cdot 028\right)$.

We examined whether exclusion of these children affected sex differences in the development quotients reported above and found they remained essentially unaltered.

Morbidity and gender differences in psychosocial development. We wanted to determine whether boys and girls with similar morbidity factors have consistently different development quotients. We therefore tested the effect of sex on development quotients at 1 and 2 years after allowing for the effect of postnatal morbidity.

The following morbidity factors related to gender formed set 1: maternal age, multiple birth, type of delivery, Apgar score at five minutes, recurrent attacks of apnoea, recurrent episodes of bradycardia, transient tachypnoea, pneumonia, ventilation, peak ventilation pressures, treatment with oxygen, blood transfusion, Intralipid infusion, serum calcium

Table 2 Gender differences in developmental quotients at 1 and 2 years (corrected for prematurity). Values are mean (SD)

\begin{tabular}{|c|c|c|c|c|}
\hline & Boys & Girls & $t$ & $\begin{array}{l}p \\
\text { Value }\end{array}$ \\
\hline \multicolumn{5}{|c|}{$\begin{array}{l}\text { Knobloch developmental scales } \\
\quad(1 \text { year assessment) }\end{array}$} \\
\hline $\begin{array}{l}n= \\
\text { General development }\end{array}$ & 82 & 99 & & \\
\hline quotient & $109 \cdot 01(17 \cdot 71)$ & $115 \cdot 19(16 \cdot 91)$ & $-2 \cdot 39$ & $<0.05$ \\
\hline Adaptive & $107.65(16.09)$ & $113.13(17.94)$ & $-2 \cdot 16$ & $<0.05$ \\
\hline Fine motor & $111.08(22.68)$ & $117.73(19.56)$ & -2.09 & $<0.05$ \\
\hline Language & $110.41(24.54)$ & $118.42(25.40)$ & $-2 \cdot 15$ & $<0.05$ \\
\hline Personal social & $115 \cdot 87(20 \cdot 85)$ & $123 \cdot 23(19 \cdot 17)$ & $-2 \cdot 45$ & $<0.05$ \\
\hline Gross motor & $100 \cdot 02(20 \cdot 80)$ & $103.43(20 \cdot 10)$ & $-1 \cdot 12$ & NS \\
\hline \multicolumn{5}{|l|}{$\begin{array}{l}\text { Griffith developmental scales } \\
\text { (2 year assessment) }\end{array}$} \\
\hline $\mathrm{n}=$ & 81 & 105 & & \\
\hline $\begin{array}{l}\text { General development } \\
\text { quotient }\end{array}$ & $101 \cdot 01(17 \cdot 05)$ & $107 \cdot 68(18 \cdot 28)$ & -2.57 & $<0.05$ \\
\hline Locomotor & $104.79(25.07)$ & $106 \cdot 77(22 \cdot 83)$ & -0.56 & NS \\
\hline Personal social & $103.55(21.41)$ & $116.91(25.56)$ & $-3 \cdot 88$ & $<0.001$ \\
\hline Hearing and speech & $94.88(21.64)$ & $107 \cdot 25(25 \cdot 15)$ & $-3 \cdot 60$ & $<0.001$ \\
\hline Eye and hand coordination & $100 \cdot 44(19.50)$ & $105 \cdot 54(18.89)$ & $-0 \cdot 80$ & NS \\
\hline Performance & $101 \cdot 36(20 \cdot 40)$ & $101.93(19.56)$ & -0.19 & NS \\
\hline
\end{tabular}


Table 3 Effect of sex on development quotients at 1 and 2 years after allowing for postnatal morbidity

\begin{tabular}{|c|c|c|c|c|c|c|c|c|c|}
\hline & \multicolumn{3}{|c|}{ Set 1 : morbidity factors } & \multicolumn{3}{|c|}{$\begin{array}{l}\text { Set } 2: 16 \text { morbidity factors } \\
\text { plus sex }\end{array}$} & \multicolumn{3}{|c|}{$\begin{array}{l}\text { Additional independent } \\
\text { contribution of sex }\end{array}$} \\
\hline & $\begin{array}{l}\% \text { Of } \\
\text { variance } \\
\text { explained }\end{array}$ & $\begin{array}{l}F \\
\text { value }\end{array}$ & $\begin{array}{l}p \\
\text { value }\end{array}$ & $\begin{array}{l}\% \text { Of } \\
\text { variance } \\
\text { explained }\end{array}$ & $\begin{array}{l}F \\
\text { value }\end{array}$ & $\begin{array}{l}p \\
\text { value }\end{array}$ & $\begin{array}{l}\% \text { Of } \\
\text { additional } \\
\text { variance } \\
\text { explained }\end{array}$ & $\begin{array}{l}F \\
\text { value }\end{array}$ & $\begin{array}{l}p \\
\text { value }\end{array}$ \\
\hline Knobloch developmental scales (1 year assessment) & \multicolumn{3}{|c|}{ df $16 ; 164$} & \multicolumn{3}{|c|}{ df $17 ; 163$} & \multicolumn{3}{|c|}{ df $1 ; 163$} \\
\hline General development quotient & $22 \cdot 9$ & 3.04 & $<0.001$ & $23 \cdot 8$ & 2.99 & $<0 \cdot 001$ & $0 \cdot 9$ & 1.84 & NS \\
\hline Adaptive & $18 \cdot 7$ & $2 \cdot 36$ & $<0.01$ & $19 \cdot 5$ & 2.33 & $<0 \cdot 01$ & $0 \cdot 8$ & 1.64 & NS \\
\hline Gross motor & $20 \cdot 6$ & $2 \cdot 66$ & $<0.001$ & $20 \cdot 7$ & $2 \cdot 50$ & $<0.01$ & $0 \cdot 1$ & $0 \cdot 19$ & NS \\
\hline Fine motor & $20 \cdot 2$ & $2 \cdot 59$ & $<0.01$ & $20 \cdot 9$ & $2 \cdot 54$ & $<0.01$ & 0.7 & 1.54 & NS \\
\hline Language & $13 \cdot 5$ & 1.59 & NS & $14 \cdot 7$ & 1.68 & NS & $1 \cdot 2$ & $2 \cdot 33$ & NS \\
\hline Personal social & $24 \cdot 3$ & $3 \cdot 30$ & $<0 \cdot 001$ & $25 \cdot 0$ & $3 \cdot 19$ & $<0.001$ & 0.7 & $1 \cdot 38$ & NS \\
\hline Griffith developmental scales (2 year assessment) & \multicolumn{3}{|c|}{ df $16 ; 169$} & \multicolumn{3}{|c|}{ df $17 ; 168$} & \multicolumn{3}{|c|}{ df $1 ; 168$} \\
\hline General development quotient & $23 \cdot 2$ & $3 \cdot 18$ & $<0.001$ & $23 \cdot 8$ & 3.09 & $<0.001$ & $0 \cdot 6$ & $1 \cdot 39$ & NS \\
\hline Performance & $12 \cdot 7$ & $1 \cdot 54$ & NS & $13 \cdot 2$ & 1.50 & NS & $0 \cdot 5$ & 0.87 & NS \\
\hline Locomotor & $21 \cdot 3$ & $2 \cdot 85$ & $<0.001$ & $21 \cdot 3$ & $2 \cdot 67$ & $<0.001$ & $0 \cdot 0$ & 0.06 & NS \\
\hline Eye and hand coordination & $17 \cdot 8$ & $2 \cdot 28$ & $<0.01$ & 17.9 & $2 \cdot 16$ & $<0.01$ & $0 \cdot 1$ & $0 \cdot 29$ & NS \\
\hline Hearing and speech & $20 \cdot 3$ & $2 \cdot 69$ & $<0.001$ & 23.4 & 3.03 & $<0.001$ & $3 \cdot 1$ & 6.91 & $<0 \cdot 01$ \\
\hline Personal social & $22 \cdot 6$ & 3.08 & $<0.001$ & $25 \cdot 0$ & $3 \cdot 29$ & $<0.001$ & $2 \cdot 4$ & $5 \cdot 37$ & $<0.05$ \\
\hline
\end{tabular}

and phosphate concentrations, and lowest haemoglobin concentration. These 16 morbidity factors were entered in the regression equation first. The morbidity factors plus sex were entered next to evaluate whether the increase in the regression sum of squares (when going from 16 to 17 degrees of freedom) was significantly greater than the residual mean square.

As shown in Table 3 column 3 , at 1 year there were no significant sex differences in development quotients after allowing for the effect of postnatal morbidity. Table 3 column 1 shows that the quotients are significantly predicted by the 16 morbidity factors. Now it is apparent that the lower mean development quotient in boys at 1 year (Table 2) is due to their increased neonatal morbidity. At 2 years boys still had poorer language and personal social skills than girls, irrespective of the number of problems they had had during the neonatal period (Table 3 column 3 ). However, the neonatal morbidity factors were still the best predictors of the development quotients at 1 and 2 years (Table 3 column 1). Of the 16 morbidity factors examined, those that had a significant independent linear association with the general development quotient at 1 year were: multiple birth $(\beta=0 \cdot 17, p<0 \cdot 05)$, high peak ventilation pressure $(\beta=0.19, p<0.05)$, and blood transfusions $(\beta=0.23, p<0.05)$. At 2 years high peak ventilation pressure was the only independent predictor of the general quotient $(\beta=0.22, p<0 \cdot 01)$.

\section{Discussion}

The published reports on sex differences and early childhood morbidity indicate that boys are generally more vulnerable. ${ }^{1-4}$ The present study provides additional evidence for this in a population of infants especially at risk. While it is well established that male preterm infants suffer more respiratory distress syndrome, ${ }^{7}$ a finding replicated in our own study, we find in addition that very low birthweight boys face a cluster of problems associated with poor outcome.

Overall, we found that boys had lower Apgar scores and suffered hypothermia more often than girls. These factors are accepted as antecedents of respiratory distress syndrome. The increased need for ventilation and higher peak pressures in boys is likely to explain their increased incidence of pulmonary interstitial emphysema and pneumothorax. ${ }^{15}$ These latter factors have been shown to be associated with a higher incidence of intraventricular haemorrhage, ${ }^{16} 17$ a complication that we found more often in boys. The increased use of umbilical arterial catheters and blood transfusion may simply reflect that the boys were more ill than the girls and required more blood sampling. As we have also found, however, that blood transfusion is an important predictor of neurodevelopmental disorder at 2 years ${ }^{18}$ anaemia requiring blood transfusions is possibly in itself harmful to very low birthweight babies.

The question remains why boys suffer more perinatal and neonatal insults. Different hypotheses have been put forward to explain this. They include the assumption that boys are constitutionally weaker than girls, and therefore more prone to illness, and that for a given gestational age girls are more physiologically mature than boys. For example, the female fetus has been reported as advanced in respiratory function. ${ }^{7}$ As birth weight rather than 
gestation was used as a selection criterion and boys are heavier than girls we would expect and indeed found that overall the mean gestational age of boys was one week less than that of girls. This difference was not significant in survivors and could not account for the difference we found in morbidity and development between boys and girls. In the babies who died there was also no significant difference in mean gestation.

In the period 1980-82 twice as many boys died as girls in the first year of life. Different factors seem to be associated with mortality in boys and girls - that is, boys suffer more severe respiratory problems and girls more severe necrotising enterocolitis, a finding reported previously. ${ }^{719}$ Other factors associated with increased mortality were a maternal history of previous miscarriage and non-white origin in girls and maternal pre-eclampsia in boys. As girls experience less neonatal illness than boys these social and antenatal factors may become apparent as contributors to death in girls. ${ }^{1}$

Surviving boys did not experience respiratory distress syndrome or pulmonary interstitial emphysema more than girls, but their increased incidence of episodes of recurrent apnoea, bradycardia, transient tachypnoea, and pneumonia shows their susceptibility to respiratory illness-with increased need of ventilation.

The higher incidence of hypophosphataemia and hypocalcaemia may be another general indicator that the boys were iller than the girls, as was their requirement for additional intravenous calories by Intralipid infusion. As far as we are aware no sex differences in hypocalcaemia and hypophosphataemia have been documented in premature babies. Low ionised and total calcium concentrations in whole blood have been shown to be correlated with Apgar scores at one and five minutes in premature babies. ${ }^{20}$ Our boys had lower Apgar scores at five minutes than girls, which might have resulted in lower calcium concentrations. This effect of asphyxia would, however, not explain more prolonged hypocalcaemia, and there are likely to be other associated factors.

We found that the very low birthweight boys had major neurodevelopmental abnormalities twice as often as girls. Increased incidence of handicap in boys has been reported previously. ${ }^{21}$

Our results also indicate that the differences in psychosocial development at 1 year between boys and girls were fairly small, although they reached significance. In contrast, by 2 years a more pronounced difference was apparent in language and personal social skills. Both morbidity factors and sex by itself independently contributed to these differences. A possible explanation for the differences at
2 years is that the Griffith scales might be more reliable because the greater number of items would be expected to reduce measurement error. Significant correlations, however, between the Knobloch developmental screening test and Griffith scales administered to the same children at roughly the same age have been found.

In addition to socialisation processes, constitutional factors like vulnerability to illness or neurological problems have been cited as a possible basis for early sex differences. The evidence is, however, sparse. ${ }^{3}$ Our findings indicate a substantial contribution of neonatal complications to gender differences in development at 1 and 2 years of age in a very low birthweight infant population. In a small sample of preterm infants Siegel reported associations between perinatal complications and cognitive and language development. ${ }^{22}$ Careful perusal of her paper shows that sex is another independent predictor of outcome. The variable sex has both genetic and socialisation components. A number of studies have reported that parents engage in different interaction patterns with boys and girls. ${ }^{23}$ In particular, mothers have been observed to talk more to their daughters than their sons ${ }^{23}$ and female neonates seem to be more responsive to auditory stimulation. ${ }^{24}$ The provision of appropriate toys has a positive correlation with cognitive development in boys but not in girls, while the converse is true of the effects of maternal involvement. ${ }^{22}$ One might speculate that the difference in personal social skills and language between boys and girls may have resulted from less verbal stimulation given by their mothers to boys, in particular between 1 and 2 years. A proper test of this hypothesis, however, requires a study that includes not only perinatal but also environmental factors. ${ }^{25}$

We thank the Wates Foundation and the Independent Order of Odd Fellows Manchester Unity Friendly Society for generously supporting this research and Mrs Angela McPherson for typing the manuscript.

\footnotetext{
References

1 Macfarlane A, Mugford M. Birth counts. Statistics of pregnancy and childbirth. London: HMSO, 1984;126-7.

2 Naeye RL, Burt LS, Wright DL, Blanc WA, Tatter D. Neonatal mortality, the male disadvantage. Pediatrics 1971;48:902-6.

3 Pederson FA, Bell RQ. Sex differences in pre-school children without histories of complications of pregnancy and delivery. Developmental Psychology 1970;3:10-5.

4 Williams PD, Williams AR. Factors affecting development of children at risk. Journal of Pediatr Psychol 1985;10:77-86.

5 St Geme JW Jr, Murray DL, Carter J, et al. Perinatal bacterial infection after prolonged rupture of amniotic membranes: an analysis of risk and management. J Pediatr 1984;104:608-13.

6 Office of Population, Censuses and Surveys. Congenital malformations 1983. London: HMSO, 1984. (Reference MB3 84/5.)

7 Avery ME, Fletcher DB, Williams RG. The lung and its disorders in the newborn infant. London: WB Saunders, 1981.
} 


\section{Brothwood, Wolke, Gamsu, Benson, and Cooper}

${ }^{8}$ Maccoby EE, Jacklin CN. Psychological sex differences. In: Rutter M, ed. Scientific foundations of developmental psychiatry. London: Heinemann, 1980.

9 Fuchs Schacter F, Shore E, Hodapp R, Chalfin S, Bundy C. Do girls talk earlier?: mean length of utterance in toddlers. Developmental Psychology 1972;14:388-92.

10 Bacola E, Behre FC, DeSchweintiz L, Miller HC, Mira M. Perinatal and environmental factors in late neurological sequelae. Am J Dis Child 1966;112:359-68.

1 Knobloch H, Pasamanick B, Sherard ED. A developmental screening inventory for infants. Pediatrics 1966;36:1095-112.

12 Gesell A. Armatruda CS. Developmental diagnosis. 2nd ed. New York: Hoeber, 1947.

13 Griffiths R. The abilities of young children. London: University of London Press, 1970.

${ }^{14}$ Stewart A. Assessment of the preterm infant and prognosis. In: Beard RW, Sharp F, ed. Preterm labour and its consequences. London: The Royal College of Obstetricians and Gynaecologists, 1985.

${ }^{15}$ Hart SM, McNair M, Gamsu HR, Price JF. Pulmonary interstitial emphysema in very low birth weight infants. Arch Dis Child 1983;58:612-5.

${ }^{16}$ Lipscomb AP, Reynolds EOR, Blackwell RJ, et al. Pneumothorax and cerebral haemorrhage in preterm infants. Lancet 1981;i:414-6.

17 Levene MI, Fawer DL, Lamont RE. Risk factors in the development of intraventricular haemorrhage in the preterm neonate. Arch Dis Child 1982;57:410-7.

18 Wolke D, Brothwood M, Gamsu HR, Cooper D. Prediction of normal developmental outcome in very low birthweight infants. (In press).

19 British Association for Perinatal Paediatrics and the Public Health Laboratory Service Communicable Disease Surveillance Centre. Surveillance of necrotising enterocolitis 1981-82. 1983;287:824-6.

${ }^{20}$ Scott SM, Ledenson JH. Aguanna J, Algate J, Hillman LS. Effect of calcium therapy in the sick premature infant with early neonatal hypocalcaemia. J Pediatr 1984;104:747-51.

${ }^{21}$ Rantakallio $\mathrm{P}$, von Wendt $\mathrm{L}$. Prognosis for low birth weight infants up to the age of fourteen years, a population study. Dev Med Child Neurol 1985;27:655-63.

22 Siegel L. Reproductive perinatal and environmental factors as predictors of the cognitive and language development of preterm and full term infants. Child Dev 1982;53:963-73.

${ }^{23}$ Moss HA. Sex, age and state as determinants of mother infant interaction. Merrill-Palmer Quarterly 1967;13:21-41.

${ }^{24}$ Friedman SL, Jacobs BS. Sex differences in neonatal behavioral responses to repeated auditory stimulation. Infant Behavior and Development 1981;4:175-83.

${ }^{25}$ Sameroff AJ. Early influences on development: fact or fancy? Merrill-Palmer Quarterly 1975;21:267-94.

Correspondence to Dr H R Gamsu, Department of Child Health, King's College School of Medicine and Dentistry, Denmark Hill, London SE5 8RX.

Received 3 April 1986 